Pakistan Journal of Intensive Care Medicine

eISSN: 2789-2905; pISSN: 2789-2891

www.pjicm.com

https://doi.org/10.54112/pjicm.v2021i1.4

Pak. J. Inten. Care Med., volume 2021:4

Research Article

\title{
BENEFICIAL EFFECTS OF AWAKE PRONE POSITIONING IN COVID-19 PATIENTS WITH MODERATE TO SEVERE HYPOXEMIC RESPIRATORY FAILURE
}

\section{RANA MA ${ }^{1}$, PERVAIZ $\mathbf{R}^{1}$, ARIF ${ }^{1}$, TARIQ F $^{1}$, TABBASUM SA ${ }^{1}$, SIDDIQUI MH ${ }^{2}$, RAZA ${ }^{1}$, HAFEEZ $\mathrm{MM}^{3 *}$}

\author{
${ }^{1}$ Department of Critical Care, Division of Medicine, Bahria International Hospital, Lahore, Pakistan \\ ${ }^{2}$ Associate Professor of Medicine, Akhtar Saeed Medical and Dental College, Lahore, Pakistan \\ ${ }^{3}$ Institute of Molecular Biology and Biotechnology, University of Lahore, Lahore, Pakistan \\ Corresponding author email: mansoorhafeez140@gmail.com
}

\begin{abstract}
Keywords
prone positioning,

COVID-19,

hypoxic respiratory failure,

awake prone positioning,

self-prone position,
\end{abstract}

$A R D S$,

$V / Q$ mismatch

Received $2^{\text {nd }}$ January 2021;

Revised $3^{\text {rd }}$ April 2021;

Online $5^{\text {th }}$ April 2021

\begin{abstract}
Introduction: Coronavirus disease (COVID-19) is a leading cause of acute hypoxemic respiratory failure which can progress to acute respiratory distress syndrome (ARDS). Prone positioning has been known to help in ARDS cases, but they are ventilated, deeply sedated and paralyzed. The aim of the current study was to assess the safety and potential benefits of awake prone positioning in COVID-19 patients with moderate to severe hypoxemic respiratory failure. Methods: This is a retrospective cohort study, performed at Bahira International Hospital Lahore. Record of confirmed COVID-19 patients with hypoxic respiratory failure was reviewed thoroughly to collect data. The duration, timing, frequency, tolerability, beneficial effects, and adverse events during prone positioning were recorded from the medical records before and after self-prone positioning. Results: The current analysis showed that prone positioning is supportive to maintain good saturation (92\%) as compared to keeping patients in spine position (82\%). Conclusion: It can be concluded from the current study that prone position is helpful to maintain normal oxygen saturation even on low oxygen supply, helping in quick recovery and preventing oxygen induced damage to the lungs.
\end{abstract}

the heart and abdomen. As a result, overweight patients have to suffer more when they develop ARDS. This leads to a disparity in perfusion and ventilation (V/Q mismatch), leading to a higher inhaled volume going to the anterior and apical lung units. As these areas have a comparatively less blood circulation, this causes difference between ventilation and perfusion (V/Q mismatch) and increases hypoxemia. When such patients are made to lie prone a more homogeneous distribution of ventilation happens, because the weight of the abdominal cavity and the mediastinum eliminated from the spine areas. This may reopen those closed alveoli, recruit more alveoli and improve gas exchange by decreasing the shunt fraction and improving ventilation and perfusion (Bamford et al., 2020; Slessarev et al., 2020; Telias et al., 2020). This physiological change may potentially prevent intubation and which can lead to better outcomes. It is a new strategy and demonstrates its feasibility and emerging benefits (Bamford et al., 2020; Elharrar et al., 2020; Sarma

[Cite: Rana MA, Pervaiz R, Arif B, Tariq F, Tabbasum SA, Siddiqui MH, Raza S, Hafeez MM. (2021). Beneficial effects of awake prone positioning in COVID-19 patients with moderate to severe hypoxemic respiratory failure. Pak. J. Inten. Care Med., 2021: 4 https://doi.org/10.54112/pjicm.v2021i1.4]. 
and Calfee, 2020; Slessarev et al., 2020; Telias et al., 2020). In the present study, we investigated the use of prone positioning in a cohort of non-intubated COVID-19 patients with moderate to severe hypoxemia and evaluated its safety, patients' tolerance of position, including duration and frequency, its effects on oxygenation and improvement of respiratory failure in terms of $\mathrm{SpO}_{2} / \mathrm{FiO}_{2}$ ratio. We also examined the reasons for cessation, possible adverse reactions, and their clinical outcomes as the available data had some queries about their tolerance (Ali et al., 2020; Elharrar et al., 2020; Saddique et al., 2020; Sartini et al., 2020).

\section{Materials and Methods}

This study was conducted at the HDU and ICU of Bahira Town International Hospital from 15 May 2020 to $31^{\text {st }}$ of January 2021. The study was approved by the Institutional Review Board and Ethics Committee (IRBEC) of hospital and waived the need for consent. Data were collected retrospectively from medical records.

The data of one hundred and seventy non-intubated patients $(n=170)$ was analyzed who had COVID-19 associated respiratory failure and were admitted to the intensive care unit (ICU) or high dependency unit (HDU) and had moderate to severe hypoxemia, which was defined as the requirement of more than 6 $\mathrm{L} / \mathrm{min}$ of Oxygen to maintain peripheral Oxygen saturation $\left(\mathrm{SpO}_{2}\right)$ greater than $90 \%$. The applied protocol for prone positioning and duration was a standard one that encouraged prone positioning for 8 to 10 hours per day. However, patients were generally encouraged to remain in the prone position for as long as they tolerated. In case of severe hypoxemia, a high flow nasal cannula (HFNC) was used. Oxygen parameters were monitored with oxygen saturation probes and noninvasive pressure cuffs at the standard intervals. Also, $\mathrm{SpO}_{2} / \mathrm{FiO}_{2}$ ratios were calculated before and after the prone positioning and their p-value was calculated. All variables were recorded in both supine and prone positions. Causes of aborting the procedure and adverse events, if any, such as intravenous catheter dislodgement, vomiting, pain, pressure ulcers or hemodynamic instability were also reviewed. Statistical analysis was done by using SPSS version 20 Nominal data was presented in the form of percentage and frequencies and continuous variables were compared by using paired T- test. Single tailed $P$ value less than 0.05 were considered statistically significant. The primary goal of the study was to assess the improvement of saturation and decrease in Oxygen demand and secondary outcome was the tolerability of the procedure and the duration of hospital stay.

\section{Results}

In the current study, total of one hundred and seventy patients were recruited and analyzed about their respiratory status in two positions, prone and supine. First in prone positioning and the second was in spine position. All included cases were already diagnosed to have moderate to severe covid-19 infection confirmed on PCR. In this study $51.2 \%$ of cases were male and $49.8 \%$ were females. Age of the patients were categorized into the subgroups having comparable subjects. Patients having prior respiratory illnesses were excluded from the study. (Table-1)

\begin{tabular}{|c|c|c|c|c|}
\hline VARIABLES & CONSTRUCTS & FRI & TOTAI & $P_{-1}$ \\
\hline \multirow{3}{*}{ Gender } & Male & $87(512 \%)$ & \multirow{3}{*}{170} & \multirow{3}{*}{0.569} \\
\hline & Male & $81(31.2 \%)$ & & \\
\hline & 30 To 39 & $51(30 \%)$ & & \\
\hline \multirow{4}{*}{ Age } & 40 Tо 49 & $61(35.89 \%)$ & \multirow{4}{*}{170} & \multirow{4}{*}{0.662} \\
\hline & 50 And above & $58(34.11 \%)$ & & \\
\hline & Respiratory & 0 & & \\
\hline & Problems & 0 & & \\
\hline \multirow{3}{*}{$\begin{array}{l}\text { Comorbid } \\
\text { Conditions }\end{array}$} & Non-Respiratory & & \multirow{3}{*}{170} & \multirow{3}{*}{$>0.05$} \\
\hline & $\begin{array}{l}\text { Diseases (DM, IHD, } \\
\text { HTN) }\end{array}$ & 81 & & \\
\hline & No co-morbidity & 89 & & \\
\hline Location & $H D U$ & 120 & 170 & $>0.05$ \\
\hline
\end{tabular}

1 DM= Diabetes mellitus, IHD= Ischemic heart disease, HTN= hypertension *Insignificant p value showed both male and female group were not comparable.

The average duration of prone positioning was 165 saturation was $87 \%(80 \%-93 \%)$ in supine position (30-300) minutes, and the peripheral oxygen and $96 \%(92 \%-100 \%)$ when the patients were in

[Cite: Rana MA, Pervaiz R, Arif B, Tariq F, Tabbasum SA, Siddiqui MH, Raza S, Hafeez MM. (2021). Beneficial effects of awake prone positioning in COVID-19 patients with moderate to severe hypoxemic respiratory failure. Pak. J. Inten. Care Med., 2021: 4 https://doi.org/10.54112/pjicm.v2021i1.4]. 
prone position. In supine position, patients had saturation of $85 \%$ on $60 \% \mathrm{FiO} 2$ but after 2 hours of prone positioning it improved to $94 \%$ on same $\mathrm{FiO} 2$. (Table-2) Limitations of the prone position were general discomfort, duration, low back pain (5.5\%), and fear of hypoxia (5\%). Seven patients (4.1\%) needed intubation and two patients (1.2\%) died. $84.2 \%$ of patients had no limitations and recovered from mild to moderate respiratory distress syndrome associated with the COVID-19 infection.

Table 2: Levels of Different Parameters Before and After Prone Positioning:

\begin{tabular}{cccccc} 
& \multicolumn{2}{c}{ In Supine Position } & \multicolumn{2}{c}{ In Prone Position } & \\
\cline { 2 - 3 } Parameters & $\begin{array}{c}\text { Mean } \\
(\mathrm{M})\end{array}$ & $\begin{array}{c}\text { Standard } \\
\text { Deviation } \\
\text { (S.D) }\end{array}$ & $\begin{array}{c}\text { Mean } \\
(\mathrm{M})\end{array}$ & $\begin{array}{c}\text { Standard } \\
\text { Deviation } \\
\text { (S.D) }\end{array}$ & P-VALUE* \\
$\mathrm{O}_{2}$ saturation & 87.17 & 4.83 & 96.41 & 3.96 & 0.00063 \\
$\begin{array}{c}\left(\mathrm{SpO}_{2} \%\right) \\
\mathrm{O}_{2} \text { demand } \\
\text { (litters) }\end{array}$ & 6.00 & 2.00 & 3.00 & 1.00 & 0.00011 \\
SpO2/FiO2 ratio & 87.5 & 3.5 & 95 & 4 & 0.00077 \\
& $*$ Paired t-test was used to check the significance of variance. & \\
\hline
\end{tabular}

\section{Discussion}

We analyzed oxygen saturation levels of one hundred and seventy non-intubated patients of covid-19 infection. As a whole, in our study significant adverse effects were observed. Fear of desaturation and backpain were the most important factors causing hinderance in prone positioning. Those who tolerated the prone positioning more than ten hours per day showed improvement in their oxygen saturation levels. Similar study has been done on COVID patients (Mady et al., 2020; Pavlov et al., 2020; Tabassum et al., 2020). Their mortality rate was extremely high as compared to our study due to smaller sample size and the patients needed intubation were more than $40 \%$ as compared to our study which showed only $4.1 \%$ patients that were intubated. The attraction of using awake prone position is to alleviate the need for mechanical ventilation (VIN or invasive ventilation) for patients who are at the greatest risk of needing intubation. Our study revealed that prone positioning of nonintubated hypoxemic patients of COVID-19 is possible. However, a considerable number of patients may not tolerate prolonged periods of lying prone or more than one session in this position while awake. But it was observed that after 2 hours of lying prone Oxygen saturation improved with same fraction of inspired Oxygen $\left(\mathrm{FiO}_{2}\right)$, which favors the beneficial effects of this position (Elharrar et al., 2020). Those who could not tolerate prolonged prone positioning showed worse outcome like extended stay in the hospital and greater chances of intubation as compared to those who were able to manage long duration of prone positioning. Given this observation, the clinical benefits of short durations of prone positioning durations may be limited. This study is also one of the few studies that revealed the adverse effects and complexities of prone positioning. In this cohort, we discovered no iatrogenic withdrawal of lines or tubes associated with the prone positioning. No pressure ulcers, aspiration events, or hemodynamic instabilities were found. Only few studies notified such changes and findings of these match with our results. As a whole, $84.2 \%$ of our patients were successfully and safely treated in prone position with no further monitoring.

\section{Conclusion}

From the results of above analyses, we can conclude that prone positioning in non- intubated COVID-19 patients with moderate hypoxemia is safe and beneficial in terms of improvement in hypoxia, oxygen demand and $\mathrm{Spo} 2 / \mathrm{FiO} 2$ ratio.

\section{Recommendations}

We can recommend that this therapy can be safely used in hospital ICUs, isolation rooms and even in wards. This simple technique can be adapted particularly in pandemics when the hospital resources are limited or full because of large number of critically ill patients. Mild to moderate cases can be prevented to progress to severely ill cases and need of an ICU or bed with ventilator can be prevented, especially during a pandemic when the resources are quite limited.

\section{Limitations}

The limitations of this study were deviation from the standard protocols of prone positioning due to limitation on the part of individual patients like back pain, joint stiffness and morbid obesity etc. Moreover, no randomization and no control group could be there because of a retrospective study design.

[Cite: Rana MA, Pervaiz R, Arif B, Tariq F, Tabbasum SA, Siddiqui MH, Raza S, Hafeez MM. (2021). Beneficial effects of awake prone positioning in COVID-19 patients with moderate to severe hypoxemic respiratory failure. Pak. J. Inten. Care Med., 2021: 4 https://doi.org/10.54112/pjicm.v2021i1.4]. 


\section{Conflict of interest}

The authors declared no conflict of interest.

\section{References.}

Ali, J., Ali, Q., Hafeez, M. M., \& Malik, A. (2020). Clinical features, diagnosis and treatment of COVID-19. Biological and Clinical Sciences Research Journal, 2020, e032.

Bamford, P., Bentley, A., Dean, J., Whitmore, D., and Wilson-Baig, N. (2020). ICS guidance for prone positioning of the conscious COVID patient 2020. United Kingdom: Intensive Care Society.

Elharrar, X., Trigui, Y., Dols, A.-M., Touchon, F., Martinez, S., Prud'homme, E., and Papazian, L. (2020). Use of prone positioning in nonintubated patients with COVID-19 and hypoxemic acute respiratory failure. Jama $\mathbf{3 2 3}$, 2336-2338.

Mady, A. F., Ramdan, O., Al Yousef, R., Ishag, A., Bakirova, G., Kuhail, A., ... \& Harthy, A. (2020). COVID 19 critical care training surge experience for physicians in riyadh health cluster one, Saudi Arabia. Biological and Clinical Sciences Research Journal, 2020(1), e041-e041.

Pavlov, I., He, H., McNicholas, B., Perez, Y., Tavernier, E., Trump, M. W., Jackson, J. A., Zhang, W., Rubin, D. S., and Spiegel, T. (2020). Awake Prone Positioning in Nonintubated Patients With Acute Hypoxemic Respiratory Failure Due to COVID-19: a Systematic Review and Meta-analysis.

Siddique, A., Fateh, A., Idrees, N., Ali, Q., Hafeez, M. M., \& Malik, A. (2020). The epidemics of COVID-19. Biological and Clinical Sciences Research Journal, 2020(1), e 030-e 030.

Sarma, A., and Calfee, C. S. (2020). Prone positioning in awake, Nonintubated patients with COVID-19: necessity is the mother of invention. JAMA Internal Medicine 180, 15391540.

Sartini, C., Tresoldi, M., Scarpellini, P., Tettamanti, A., Carcò, F., Landoni, G., and Zangrillo, A. (2020). Respiratory parameters in patients with COVID-19 after using noninvasive ventilation in the prone position outside the intensive care unit. Jama 323, 2338-2340.

Scholten, E. L., Beitler, J. R., Prisk, G. K., and Malhotra, A. (2017). Treatment of ARDS with prone positioning. Chest 151, 215-224.

Slessarev, M., Cheng, J., Ondrejicka, M., and Arntfield, R. (2020). Patient self-proning with high-flow nasal cannula improves oxygenation in COVID-19 pneumonia. Canadian Journal of
Anesthesia/Journal canadien d'anesthésie 67, 1288-1290.

Tabassum, S. A., Bibi, T., Tariq, F., TARIQ, S., Raza, S., Hafeez, M., \& Rana, M. (2020). Unusual leukemoid reaction in a COVID-19 patient: A case report. Biological and Clinical Sciences Research Journal, 2020(1), e034.

Telias, I., Katira, B. H., and Brochard, L. (2020). Is the prone position helpful during spontaneous breathing in patients with COVID-19? Jama 323, 2265-2267.

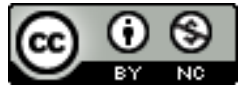

Open Access This article is licensed under a Creative Commons Attribution 4.0 International License, which permits use, sharing, adaptation, distribution and reproduction in any medium or format, as long as you give appropriate credit to the original author(s) and the source, provide a link to the Creative Commons licence, and indicate if changes were made. The images or other third party material in this article are included in the article's Creative Commons licence, unless indicated otherwise in a credit line to the material. If material is not included in the article's Creative Commons licence and your intended use is not permitted by statutory regulation or exceeds the permitted use, you will need to obtain permission directly from the copyright holder. To view a copy of this licence, visit http://creativecommons.org/licen ses/by/4.0/.

(C) The Author(s) 2021

[Cite: Rana MA, Pervaiz R, Arif B, Tariq F, Tabbasum SA, Siddiqui MH, Raza S, Hafeez MM. (2021). Beneficial effects of awake prone positioning in COVID-19 patients with moderate to severe hypoxemic respiratory failure. Pak. J. Inten. Care Med., 2021: 4 https://doi.org/10.54112/pjicm.v2021i1.4]. 